\title{
Synapsin I Is Associated with Cholinergic Nerve Terminals in the Electric Organs of Torpedo, Electrophorus, and Malapterurus and Copurifies with Torpedo Synaptic Vesicles
}

\author{
W. Volknandt, ${ }^{*}$ S. Naito, ${ }^{*}$ T. Ueda, and H. Zimmermann \\ AK Neurochemie, Zoologisches Institut der J. W. Goethe-Universität, Frankfurt am Main, F.R.G.; and \\ *Mental Health Research Institute, University of Michigan, Ann Arbor, Michigan, U.S.A.
}

\begin{abstract}
Using an affinity-purified monospecific polyclonal antibody against bovine brain synapsin I, the distribution of antigenically related proteins was investigated in the electric organs of the three strongly electric fish Torpedo marmorata, Electrophorus electricus, Malapterurus electricus and in the rat diaphragm. On application of indirect fluorescein isothiocyanate-immunofluorescence and using $\alpha$-bungarotoxin for identification of synaptic sites, intense and very selective staining of nerve terminals was found in all of these tissues. Immunotransfer blots of tissue homogenates revealed specific bands whose molecular weights are similar to those of synapsin Ia and synapsin Ib. Moreover, synapsin I-like proteins are still attached to the synaptic ves-
\end{abstract}

icles that were isolated in isotonic glycine solution from Torpedo electric organ by density gradient centrifugation and chromatography on Sephacryl-1000. Our results suggest that synapsin I-like proteins are also associated with cholinergic synaptic vesicles of electric organs and that the electric organ may be an ideal source for studying further the functional and molecular properties of synapsin I. Key Words: Synapsin I-Protein I-Torpedo-Synaptic vesicles-Acetylcholine-Electrophorus-Malapterurus. Volknandt $W$. et al. Synapsin I is associated with cholinergic nerve terminals in the electric organs of Torpedo, Electrophorus, and Malapterurus and copurifies with Torpedo synaptic vesicles. J. Neurochem. 49, 342-347 (1987).
The phosphoprotein synapsin I, previously named protein I, refers to two polypeptides (synapsin Ia and synapsin Ib) with apparent molecular weights of 86,000 and 80,000 (Ueda and Greengard, 1977). Synapsin $I$ is exclusively present in the nervous system where it is primarily associated with nerve terminals at the great majority of synapses (De Camilli et al., $1983 a$ ). Inside the nerve terminals it is mainly bound to synaptic vesicles as revealed by subcellular fractionation (Ueda et al., 1979; Huttner et al., 1983) or immunoelectron microscopy (De Camilli et al., 1983b). Outside the CNS synapsin I has been shown to be localized, e.g., in the posterior pituitary, the retina, the superior cervical, and the ciliary ganglion and the neuromuscular junction (Ueda and Naito, 1982; de Camilli et al., 1983a).
Recently synapsin I has been implicated in regulating neurotransmitter release by controlling the availability of synaptic vesicles for exocytosis (Llinas et al., 1985). Furthermore a close similarity between synapsin I and the erythrocyte membrane skeletal protein, protein 4.1 , has been described and points to possible interactions of synapsin I with cytoskeletal components of the nerve terminal (Baines and Bennet, 1985, 1986).

The general distribution of synapsin I in brain nerve terminals and also in nerve terminals of peripheral ganglia and the neuromuscular junction suggests that this protein is also associated with cholinergic synaptic vesicles. However, the demonstration of an association of synapsin I with nerve terminals in the electric ray electric organ, the source of the hitherto best stud-
Received September 29, 1986; accepted January 13, 1987

Address correspondence and reprint requests to Dr. H. Zimmermann at AK Neurochemie, Zoologisches Institut der J. W. GoetheUniversität, Siesmayerstraße 70, Postfach 11 19 32, D-6000 Frankfurt am Main, F.R.G.

The present address of Dr. S. Naito is Laboratory of Biophysics
NIH-NINCDS, Marine Biology Laboratories, Woods Hole, MA 02543, U.S.A.

Abbreviations used: $\mathrm{ACh}$, acetylcholine; BSA, bovine serum albumin; FITC, fluorescein isothiocyanate; NP-40, Nonidet P-40; SDS, sodium dodecyl sulfate; TBSA, Tris-buffered saline containing $1 \%(\mathrm{wt} / \mathrm{vol})$ bovine serum albumin. 
ied synaptic vesicles, has so far been unsuccessful. We report here evidence, produced using an affinity-purified polyclonal antibody against bovine brain cerebral cortex synapsin I, for the presence of synapsin I-like proteins in cholinergic nerve terminals, not only in the electric organs of the electric ray Torpedo marmorata but also in those of the electric eel (Electrophorus electricus) and the electric catfish (Malapterurus electricus). Furthermore, it will be shown that synapsin I is still associated with synaptic vesicles purifed from the Torpedo electric organ in isotonic glycine solutions.

\section{MATERIALS AND METHODS}

\section{Animals}

Electric rays (Torpedo marmorata) obtained from the Institut Universitaire de Biologie Marine, Arcachon, France, and electric eels (Electrophorus electricus) and electric catfish (Malapterurus electricus) obtained from local fish dealers were kept as described previously by Volknandt and Zimmermann (1986). Prior to excision of electric organs, electric rays were anesthetized by chilling on ice for $20 \mathrm{~min}$ and electric catfish anesthetized with tricaine methanesulfonate $0.05 \%$ (wt/vol) (Sigma). Electric eels and male Wistar rats (approximately $200 \mathrm{~g}$ ) were decapitated prior to excision of tissues.

\section{Subcellular fractionation}

Synaptic vesicles were isolated on isotonic glycine/sucrose gradients essentially as described by Schmidt et al. (1980) and harvested on top of the $0.4 M$ sucrose layer. For further fractionation, the vesicle fraction purified by density gradient centrifugation was diluted $1: 4(\mathrm{wt} / \mathrm{vol})$ in an isotonic glycine solution $(0.8 \mathrm{M}$ glycine, $\mathrm{Tris} / \mathrm{HCl}, \mathrm{pH} 7.4)$ and recentrifuged for $60 \mathrm{~min}$ at $190,000 \mathrm{~g}_{\mathrm{av}}$. The pellet derived from $45 \mathrm{~g}$ of starting tissue was resuspended in $2.5 \mathrm{ml}$ of the isotonic glycine solution containing $1 \mathrm{~m} M$ EGTA. Two milliliters of this pellet fraction were then loaded onto a Sephacryl-1000 column (Pharmacia) $(85 \times 1.6 \mathrm{~cm}, 15 \mathrm{ml} /$ h) previously equilibrated with the above isotonic glycine solution. Fractions of $1.95 \mathrm{ml}$ were collected by means of a fraction collector.

\section{Analytical procedures}

Acetylcholine (ACh), ATP, and protein in subcellular fractions were determined as described previously by Volknandt and Zimmermann (1986).

Binding of synapsin I antibodies was determined using a dot-immunobinding assay as described previously by Volknandt and Zimmermann (1986). In the present experiments, antigen corresponding to $200 \mu \mathrm{l}$ of column fraction was dotted on a nitrocellulose filter. The binding of the first antibody [anti-synapsin I, diluted 1:500 in $5 \mathrm{mM}$ Tris/HCl $(0.6 \mu \mathrm{g}$ of protein $/ \mathrm{ml}), \mathrm{pH} 7.5$, containing $3 \%(\mathrm{wt} / \mathrm{vol}$ ) bovine serum albumin (BSA)] was performed overnight at $4^{\circ} \mathrm{C}$. The paper was then washed in blot buffer [ $50 \mathrm{mM}$ Tris/ $\mathrm{HCl}, \mathrm{pH} 7.4 ; 150 \mathrm{mM} \mathrm{NaCl} ; 5 \mathrm{~m} M$ EDTA; $0.25 \%$ (wt/vol) gelatin; $0.05 \%$ (wt/vol) Nonidet P-40 (NP-40); $0.2 \%$ (wt/vol) $\mathrm{NaN}_{3}$ ] followed by application of the second iodinated antibody $\left({ }^{125} \mathrm{I}\right.$-anti-rabbit Ig, $\mathrm{F}\left(\mathrm{ab}^{\prime}\right)_{2}$ fragment, donkey, Amersham). This was followed by several washes in sodium dode- cyl sulfate (SDS) blot buffer [0.1\% (wt/vol) SDS and $0.5 \%$ (wt/vol) NP-40] until no radioactivity could be detected in the washing solution. After drying, the dots were excised and binding activity determined in a Philips PW 4800 gamma counter. The first antibody was affinity-purified rabbit anti-synapsin I (bovine brain) IgG (Naito and Ueda, 1983).

\section{Immunotransfer blotting}

Tissue was homogenized in ice-cold $1 \%(\mathrm{wt} / \mathrm{vol})$ SDS solution ( $10 \mu \mathrm{l} / \mathrm{mg}$ of wet weight) by means of an Ultra-Turrax homogenizer, boiled for $5 \mathrm{~min}$, and stored on ice. Sample buffer was added to this suspension to yield a final concentration of $0.4 \%$ (wt/vol) SDS; $80 \mathrm{~m} M$ Tris $/ \mathrm{HCl}, \mathrm{pH} 6.8 ; 1 \%$ (wt/vol) glycerol; and $0.0012 \%(\mathrm{wt} / \mathrm{vol})$ bromphenol blue. Prior to use, dithiothreitol was added to yield a final concentration of $0.1 \mathrm{M}$. Vesicle peak fractions corresponding to $84-108 \mathrm{ml}$ and void volume fractions corresponding to $60-$ $80 \mathrm{ml}$ of the Sephacryl-1000 eluant were each combined and pelleted at $190,000 \mathrm{~g}_{\mathrm{av}}$ for $60 \mathrm{~min}$. The pellet was resuspended directly in the sample buffer (final concentrations as described above). The sample solution was then boiled for $3 \mathrm{~min}$ and cooled on ice before incubation in the presence of $0.2 \mathrm{M}$ iodoacetamide for $1 \mathrm{~h}$ at room temperature to block free sulfhydryl groups. SDS-polyacrylamide gel electrophoresis was performed according to Laemmli (1970) on minigels (thickness $0.5 \mathrm{~mm}$ ). Proteins were then transferred onto nitrocellulose paper for $2 \mathrm{~h}$ at $450 \mathrm{~mA}$ [transfer buffer: $192 \mathrm{~m} M$ glycine; $1 \mathrm{~m} M$ EDTA; $0.05 \%$ (wt/vol) SDS; $20 \%$ (vol/vol) methanol; and $25 \mathrm{mM}$ Tris/HCl, $\mathrm{pH}$ 8.6]. After transfer, protein standards were cut out and stained with Ponceau S (Sigma). The nitrocellulose was incubated with $5 \mathrm{~m} M$ Tris/HCl, pH 7.5, containing 3\% (wt/vol) BSA, for 1 $h$. Binding of affinity purified anti-synapsin I antibody diluted 1:500 in $5 \mathrm{mM}$ Tris/ $\mathrm{HCl}(0.6 \mu \mathrm{g}$ of protein/ml $)$ containing 3\% (wt/vol) BSA was performed overnight. After five washes with $5 \mathrm{~m} M$ Tris solution, the second iodinated antibody ( ${ }^{125} \mathrm{I}$-anti-rabbit Ig $\mathrm{F}\left(\mathrm{ab}^{\prime}\right)_{2}$ fragment, donkey, Amersham, $0.5 \mu \mathrm{Ci} / \mathrm{ml}$ blot buffer) was applied for $2 \mathrm{~h}$ at room temperature. This was followed by several washes with SDS blot buffer until no radioactivity could be detected in the washing solution. After drying at room temperature, the sheets of nitrocellulose were exposed to x-ray films (Hyperfilm MP, Amersham). X-ray films were developed in Kodak D 19 and photographed.

\section{Immunohistochemistry}

Small pieces of electric organ or of rat diaphragm were fixed in cacodylate-buffered $(0.4 \mathrm{M}, \mathrm{pH} 7.4$, for electric ray, or $0.1 \mathrm{M}, \mathrm{pH} 7.4$, for electric eel, electric catfish, and rat) paraformaldehyde $(4 \%, w t / v o l)$ for $2 \mathrm{~h}$ at room temperature. After three washes in the above cacodylate solutions, blocks were stored overnight in cacodylate solution containing $20 \%$ (wt/vol) sucrose. After freezing in liquid nitrogen, $10-\mu \mathrm{m}$ cryostat-sliced sections were treated sequentially with (1) $5 \mathrm{~m} M$ Tris/HCl, $\mathrm{pH} 7.5[0.1 \%$ (wt/vol) Triton X100] for $30 \mathrm{~min}$; (2) $5 \mathrm{mM}$ Tris/ $\mathrm{HCl}$, pH 7.5, containing $10 \%$ (wt/vol) nonimmune sheep serum for $40 \mathrm{~min}$; (3) first antibody, affinity-purified anti-synapsin $I\{0.15 \mu \mathrm{g} /$ slide, with 1:50 diluted rhodamine-conjugated $\alpha$-bungarotoxin in a solution of $10 \%$ ( $\mathrm{vol} / \mathrm{vol}$ ) TBSA [0.15 M NaCl, $10 \mathrm{mM}$ Tris/ $\mathrm{HCl}$ ( $\mathrm{pH} 7.4$ ), containing $1 \%$ (wt/vol) BSA and $5 \mathrm{mM}$ Tris/ $\mathrm{HCl}(\mathrm{pH} \mathrm{7.5)] \}}$ for $60 \mathrm{~min}$. The sections were then washed with $5 \mathrm{mM}$ Tris/ $\mathrm{HCl}, \mathrm{pH} 7.5$, solution and incu- 
bated for $30 \mathrm{~min}$ with fluorescein isothiocyanate (FITC)conjugated affinity-purified second antibody [affinity-isolated antigen-specific anti-rabbit IgG (whole molecule, goat, Sigma) diluted 1:50 in $10 \%$ (wt/vol) TBSA in $5 \mathrm{mM}$ Trisbuffer]. Sections were washed and mounted in $0.1 \mathrm{M}$ phosphate buffer, $\mathrm{pH}$ 8.5. Immunofluorescence was performed using standard procedures and a Zeiss Photomicroscope III.

\section{RESULTS}

\section{Immunocytochemical analysis}

The distribution of anti-synapsin I antibody binding sites in all tissues investigated is strictly restricted to the presynaptic site. The Torpedo electric organ revealed a clear staining pattern of the final ramifications of axon terminals (Fig. 1). There is also faint staining of the axon collaterals between electroplaque cells. Staining of electroplaque cells is completely absent and no staining occurs with preimmune sera (not shown). In Torpedo, the distribution of nicotinic acetylcholine receptors, as revealed by binding of rhodamine-conjugated $\alpha$-bungarotoxin, marks the same sites but is more regular. This suggests that the receptors cover the entire postsynaptic membrane and are not restricted to subsynaptic sites only.

In the electric eel electric organ, the antibody selectively stains the various nerve terminals running along the folds of the caudal surface of the electroplaque cell. The distribution of $\alpha$-bungarotoxin exactly coincides with this pattern (Fig. 2). Interestingly, the distribution of $\alpha$-bungarotoxin binding sites at the level of individual nerve terminal varicosities results in ringlike structures, whereas synapsin I binding sites are equally distributed over the nerve terminals.

An identical result is obtained with the nerve terminals in the electric catfish electric organ (Fig. 3). In this tissue, the focal synapses are restricted to the terminal knob of a stalk-like caudal process of the electroplaque cell (Janetzko et al., 1987).

Figure 4 underlines the specificity of the antibody binding. The staining of the nerve terminals in the rat neuromuscular junction (diaphragm) are similar to the results obtained previously by De Camilli et al. $(1983 a)$. The faint background fluorescence of muscle fibers in Fig. 4 is a property of the tissue and not related to application of antibodies.

\section{Identification of antibody-binding constituents of intact tissue}

For identification of antibody-binding components total tissue homogenates were separated by SDS-polyacrylamide gel electrophoresis. Antibody binding was determined after transfer of proteins to nitrocellulose paper and autoradiography (Fig. 5). With all tissues (electric organs of Torpedo, Electrophorus, Malapterurus, and for comparison rat cortex and rat diaphragm), selective bands were revealed in the autoradiograms. The rat cortex and diaphragm showed a typical doublet of synapsin I; apparent molecular masses of these polypeptides were determined to be 72 $\mathrm{kD}$ and $75 \mathrm{kD}$, respectively, on this gel. The Torpedo electric organ revealed a single polypeptide of a higher molecular mass $(80 \mathrm{kD})$. Occasionally a very faint second band at $84 \mathrm{kD}$ was observed in Torpedo electric organ extracts. In contrast electric eel electric organs showed a doublet $\left(M_{r}=72,000\right.$ and 76,000$)$ whereas the electric catfish revealed a single band $\left(\mathrm{M}_{\mathrm{r}}\right.$ $=72,000)$. This suggests that the specific staining of tissues (Figs. 1-4) is due to the presence of specific synapsin I-like proteins.

\section{Subcellular fractionation}

To evaluate whether the synapsin I-like protein was associated with synaptic vesicles, we isolated fractions of synaptic vesicles from Torpedo electric organ and analyzed them by both dot-blotting and immunotransfer blotting. Since synapsin I becomes dissociated from synaptic vesicles by elevated salt solutions (Ueda and Greengard, 1977; Huttner et al., 1983), vesicles were purified in isotonic $(0.8 M)$ glycine solution. Synaptic vesicles were first purified by sucrose density gradient centrifugation. To separate vesicles from possible membrane contaminants, the vesicle fraction obtained by density gradient centrifugation (band sedimenting on top of a $0.4 \mathrm{M}$ sucrose solution) was further purified by column chromatography on Sephacryl-1000.

As shown by the distribution of the vesicle markers ACh and ATP (Fig. 6), the main vesicle peak elutes around $100 \mathrm{ml}$. There is a large protein peak in the excluded volume of the column and a smaller one eluting with synaptic vesicles. Antibody binding activity (immunodot assay) is present both in the void volume portion of the column eluate and in the vesicle peak.

Immunotransfer blotting of the vesicle fraction isolated by density gradient centrifugation (sv, Fig. 7) demonstrates that the antibody binding protein of $\mathrm{M}_{\mathrm{r}}$ $=80,000$ detected in intact tissue is associated with synaptic vesicles. On subsequent column chromatography performed overnight partial proteolytic degradation of the antibody binding protein took place. Samples from the void volume and the vesicle peak fractions reveal a similar binding pattern for the antisynapsin I antibody in the autoradiogram. These samples contained a $72-\mathrm{kD}$ protein in addition to the $80-$ $\mathrm{kD}$ protein.

\section{DISCUSSION}

Our results suggest that proteins antigenically related to synapsin I are associated with nerve terminals in the Torpedo, Electrophorus, and Malapterurus electric organs. There are, however, differences among species both with regard to the expression of the synapsin I doublet and the molecular weight of 

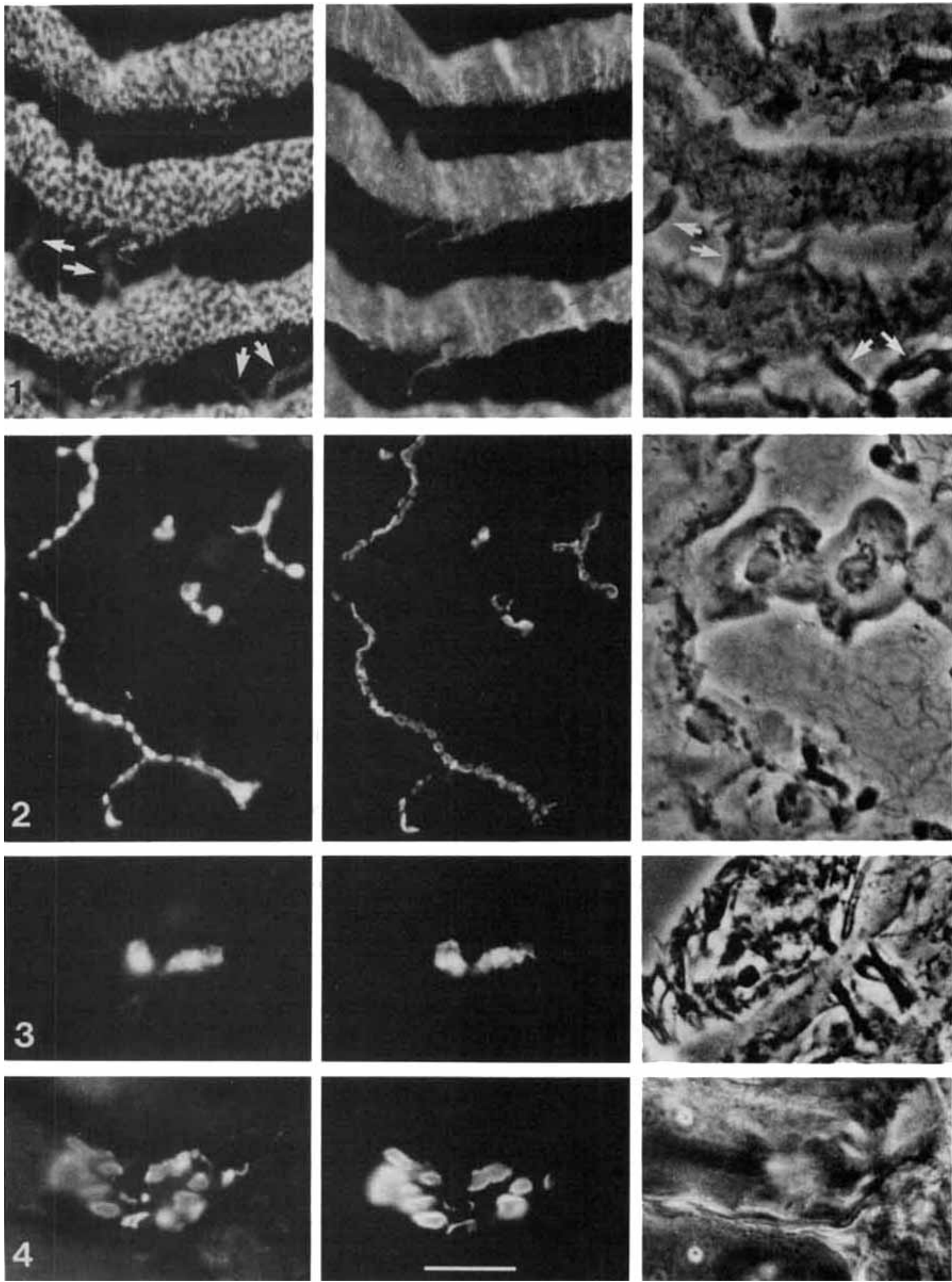

FIGS. 1-4. Staining of nerve terminal regions in the electric organs of Torpedo (1), Electrophorus (2), and Malapterurus (3) and in the diaphragm of the rat (4) with anti-synapsin I antibody. Left: Immunofluorescence using FITC-labelled second antibody. Middle: Identical image with binding of rhodamine-conjugated $\alpha$-bungarotoxin. Right: Corresponding phase-contrast image. Arrows indicate axons between Torpedo electroplaque cells apparent in immunofluorescence and phase contrast but not with $\alpha$-bungarotoxin. Bar $=20 \mu \mathrm{m}$. 


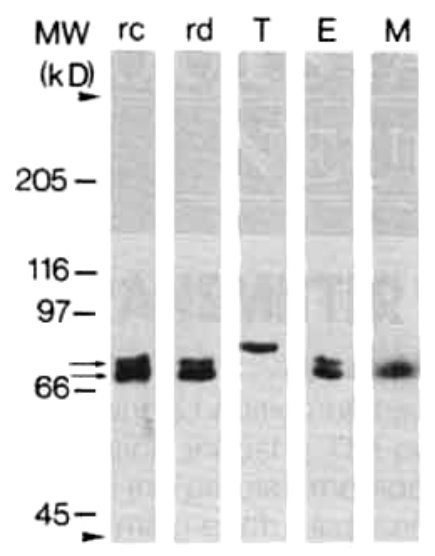

FIG. 5. Immunotransfer blots of tissue homogenates of rat cortex (rc); rat diaphragm (rd); and electric organs of Torpedo marmorate (T), Electrophorus electricus (E), and Malapterurus electricus (M). Binding of anti-synapsin I antibody. Autoradiography was performed with ${ }^{125}$-labelled second antibody. Between 30 and $80 \mu \mathrm{g}$ of protein were applied per slot. MW, molecular weight standards in kilodalton (kD); small arrows, synapsin la and lb; arrowheads, borderlines of running gel.

synapsin I-like proteins. Synapsin I-like proteins may vary with regard to apparent molecular weight among species. Our results are in accordance with the observation (Goelz et al., 1985) that proteins antigenically related to synapsin I have a wide distribution in the animal kingdom ranging from starfish and insects to mammals.

The ease with which synapsin I is dissociated from the membrane by saits (Ueda and Greengard, 1977; Huttner et al., 1983) has presented a problem for the purification of synapsin I-bound synaptic vesicles from the electric ray electric organ. Electric rays have a high osmolarity of tissue fluids. During subcellular fractionation this is normally maintained by use of a $0.4 M$ saline solution (Zimmermann, 1982). We have shown that when synaptic vesicle purification is carried out in isotonic glycine medium, synapsin I-like $(80 \mathrm{kD})$ protein remains associated with synaptic vesicles.
FIG. 7. Immunotransfer blots of subcellular fractions obtained from Torpedo electric organ. sv, synaptic vesicle fraction purified by density gradient centrifugation. Further fractionation of vesicle fraction (sv) was performed as shown in Fig. 5 by chromatography on Sephacryl-1000 with void volume fraction (vv) and $A C h$ and ATP peak fraction (vp). Between 7 and $16 \mu 9$ of protein were applied per slot. MW, molecular weight standards in kilodalton (kD); arrowheads. borderlines of running gel.

It is interesting to note, however, that on column chromatography, it is degraded to a smaller molecular weight species $\left(M_{r}=72,000\right)$, which corresponds to the synapsin Ia component in the rat brain and diaphragm. It is not clear at the moment whether the anti-synapsin I antibody binding proteins in the void volume fractions of the Sephacryl-1000 column represent synapsin I bound to aggregated synaptic vesicles or membranes other than synaptic vesicles or whether the binding proteins are soluble and trapped in larger membrane vesicles.

For the electric organs of Electrophorus and $\mathrm{Ma}$ lapterurus which carry a much less dense innervation than Torpedo, and whose synaptic vesicles have not yet been purified to homogeneity (Volknandt and Zimmermann, 1986), synapsin I may be a useful tool for application of immunoaffinity techniques for vesicle purification. This method has been successfully applied in the purification of synapsin I-containing brain vesicles and the demonstration of an ATP-dependent glutamate uptake system (Naito and Ueda, 1983, 1985).

Since the Torpedo electric organ is a system well defined for the study of synaptic vesicle molecular composition and neurotransmitter release (Zimmermann, 1982), this tissue may be an ideal source to further study the cellular function of synapsin I.

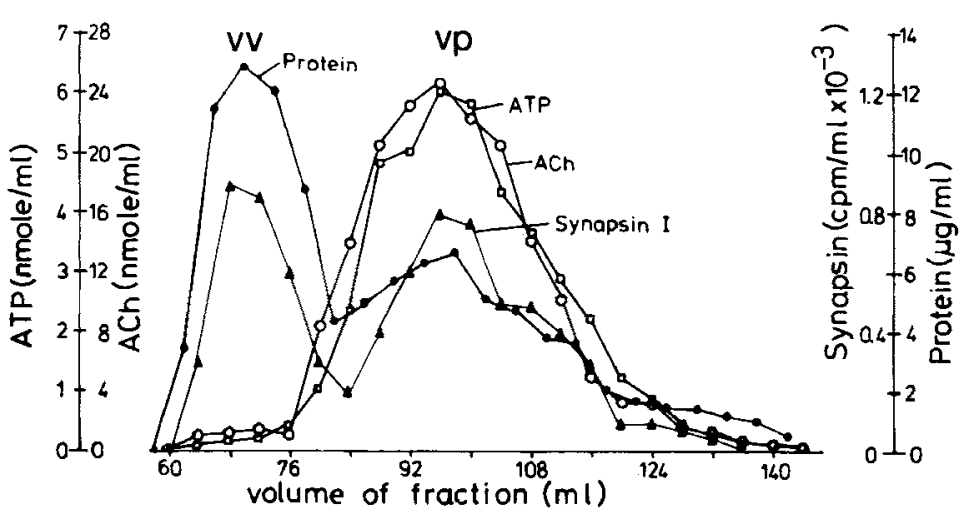

FIG. 6. Binding activity of anti-synapsin I antibody to synaptic vesicles that were purified from Torpedo electric organ by sucrose density gradient centrifugation and eluted from a column of Sephacryl-1000. The main protein $(\Theta)$ peak marks the volume excluded from the column (vv). ACh (O) and ATP (प) are retarded and form a coincident peak (vp). Binding activity for synapsin I $(\Delta)$ is apparent in both peaks. Four hundred and twenty micrograms of protein were loaded onto the column. The specific activity of $\mathrm{ACh}$ (nmol/mg protein) in the vesicle peak fraction was 4,110 . 
Acknowledgment: We are grateful to Annemarie Polotzek for typing the manuscript and to the Deutsche Forschungsgemeinschaft (Zi 140/7-1 and SFB 169/A11) and NIH (Grant NS 15113, T.U.) for financial support.

\section{REFERENCES}

Baines A. J. and Bennet V. (1985) Synapsin I is a spectrin-binding protein immunologically related to erythrocyte protein 4.1 . Nature 315, 410-413.

Baines A. J. and Bennet V. (1986) Synapsin I is a microtubulebundling protein. Nature $319,145-147$

De Camilli P., Cameron R., and Greengard P. (1983a) Synapsin I (protein I), a nerve terminal-specific phosphoprotein. I. Its general distribution in synapses of the central and peripheral nervous system demonstrated by immunofluorescence in frozen and plastic sections. J. Cell Biol. 96, 1337-1354.

De Camilli P., Harris S. M., Huttner W. B., and Greengard P. (1983b) Synapsin I (protein I), a nerve terminal-specific phosphoprotein. II. Its specific association with synaptic vesicles demonstrated by immunocytochemistry in agarose-embedded synaptosomes. J. Cell Biol. 96, 1355-1373.

Goelz S. E., Nestler E. J., and Greengard P. (1985) Phylogenetic survey of proteins related to synapsin I and biochemical analysis of four such proteins from fish brain. J. Neurochem. 45, 6372.

Huttner W. B., Schiebler W., Greengard P., and De Camilli P. (1983) Synapsin I (Protein I), a nerve terminal-specific phosphoprotein. III. Its association with synaptic vesicles studied in a highly purified synaptic vesicle preparation. $J$. Cell Biol. 96 , $1374-1388$.

Janetzko A., Zimmermann H., and Volknandt W. (1987) The electromotor system of the electric catfish (Malapterurus electricus). A fine structural analysis. Cell Tissue Res. 247, 613-624.

Laemmli U. K. (1970) Cleavage of structural proteins during the assembly of the head of bacteriophage $T_{4}$. Nature 227,680 685.

Llinas R., McGuiness T. L., Leonard C. S., Sugimori M., and Greengard P. (1985) Intraterminal injection of synapsin I or calcium/calmodulin-dependent protein kinase II alters neurotransmitter release at the squid giant synapse. Proc. Natl. Acad. Sci. USA 82, 3035-3039.

Naito S. and Ueda T. (1983) Adenosine triphosphate-dependent uptake of glutamate into protein I-associated synaptic vesicles. J. Biol. Chem. 258, 696-699.

Naito S. and Ueda T. (1985) Characterization of glutamate uptake into synaptic vesicles. J. Neurochem. 44, 99-109.

Schmidt R., Zimmermann H., and Whittaker V. P. (1980) Metal ion content of cholinergic synaptic vesicles isolated from the electric organ of Torpedo: effect of stimulation-induced transmitter release. Neuroscience 5, 625-638.

Ueda T. and Greengard P. (1977) Adenosine 3':5'-monophosphateregulated phosphoprotein system of neuronal membranes. I. Solubilization, purification, and some properties of an endogenous phosphoprotein. J. Biol. Chem. 252, 5155-5163.

Ueda T. and Naito S. (1982) Specific inhibition of the phosphorylation of protein I, a synaptic protein, by affinity-purified antiprotein I antibody. Prog. Brain Res. 56, 87-103.

Ueda T., Greengard P., Berzins K., Cohen R. S., Blomberg F., Grab D. J., and Siekevitz P. (1979) Subcellular distribution in cerebral cortex of two proteins phosphorylated by cAMP-dependent protein kinase. J. Cell Biol. 83, 308-319.

Volknandt W. and Zimmermann H. (1986) Acetylcholine, ATP and proteoglycan are common to synaptic vesicles isolated from the electric organs of electric eel and electric catfish as well as from rat diaphragm. J. Neurochem. 47, 1449-1462.

Zimmermann H. (1982) Biochemistry of the isolated cholinergic vesicles, in Neurotransmitter Vesicles (Klein R. L., Lagercrantz H., and Zimmermann H., eds), pp. 271- 304. Academic Press, London. 